\title{
Comparitive Study between Conventional Laparscopic Cholecystectomy Versus Cholecystectomy Utilizing Energy Sealing Devices
}

A.A.Yousef, H.G.El-Gohary, M.E.Abd El-latif and M.S.Abd Elhady

General Surgery Dept., Faculty of Medicine, Benha Univ., Benha, Egypt

E-Mail: M.Abd_Elhady@gmail.com

\begin{abstract}
LC is the gold standard treatment for gallstones. Ultrasonic scalpel, which causes three synergically acting effects: cavitation, coaptation / coagulation and cutting. to Compare between laparoscopic cholecystectomy utilizing energy sealing devices (clipless) and conventional laparoscopic cholecystectomy as regard operative time, pain, infection, bile leakage ,early post-operative recovery, hospital stay ,the need for drain .... etc. This was a prospective study, which was performed at the General Surgery Department of Benha University Hospital after approval by the Benha Faculty of Medicine Research Ethical Committee, and all patients signed informed consent to be included in this study. As far as our analysis in Group A was concerned, mean hospital stay (in days) was (2.21) while mean hospital stay (in days) was (2.24) in Group B, there is no statistically significant difference in hospital stay between the two groups. In Group A: postoperative infection occurred in one case, in Group B postoperative infection occurred in 2 cases, and in both groups there was no postoperative bile leakage. The energy sealing system offers full hemobiliar stasis to all patients and is a healthier alternative to traditional cystic duct and artery video. It has a shorter processing time, decreased blood loss and decreased transfer rate for open cholecystectomy.
\end{abstract}

Keywords: Laparoscopic, Conventional, Ultrasonic Scalpel, Operative, Hemobiliary.

\section{Introduction}

The modern LC is usually performed with dissecting, electro-surgical instruments as spatula, and/or scissors, and this procedure has been used in most of the centres. Clear metal clips are also used for the closing of cystic ducts and arteries. Alternative technique with sutures to close cyst ducts is rarely used [1].

While the surgical clip was considered a safe form of closure, bile leakage is a potential risk of laparoscopic cholecystectomy due to the displacement of the clip from the stump in the cystic duct. There are also other dangers involved with the use of clips, such as unintended cutting of typical bile duct, leading to blocking, stretching, slicing, etc [2].

As a result, many conventional methods are often used to control the cystic artery, such as absorbable or non-absorbable sutures; monopolar or bipolar electro coagulation and energy sealing devices have also been used for this purpose, but energy sealing devices have been used less commonly due to their high cost [3].

Ultrasound-activated energy sealing systems, developed as a safe alternative to haemostatic tissue dissection electrocautery, were put into clinical use nearly a decade ago.it is stated that ultrasound dissection is efficient and easy to implement [4].

Energy sealing systems are also an important means of closing cystic ducts and vessels with a diameter less than $4 \mathrm{~mm}$ (as FDA certified in 2006). This research was conducted to show the effectiveness and safety of energy sealing devices as the only tool for the laparoscopic cholecystectomy procedure to achieve complete hemobiliary stasis. In addition, the use of a single instrument [5].

\section{2. patient and methods}

A prospective study, which was performed at the General Surgery Department of Benha University Hospital after approval by the Scientific Ethics
Committee of the Faculty of Medicine in Benha, and all patients signed informed consent to be included in it research.

A total of 42 patients with history of Chronic Calcular Cholecystitis have been enrolled in our postoperative follow-up study from January 2018 to December 2018.

\section{Inclusion criteria}

All patients with history of Chronic Calcular Cholecystitis and Patients from 18-60 years old.

\section{Exclusion criteria}

Age less than 18 or more than 60 years and wide cystic duct, mirizzi syndrome and patients with history of obstructive jaundice .

All patients meeting the inclusion criteria were subjected to our study after proper history taking, full clinical examination, and required preoperative laboratory investigations as whole blood image, liver function test, $\mathrm{HCV}$ and $\mathrm{HBV}$ markers and also imaging as abdominal ultrasound and MRCP .

Closed envelop randomization or card system our patients was randomized into two groups:

- Group A: (22 patients) underwent clipless laparoscopic cholecystectomy.

- Group B: (20 patients) underwent conventional laparoscopic cholecystectomy.

- $\quad$ N.B: 2 patients from group A underwent clipless laparoscopic cholecystectomy but intraoperative bile leak noted from gallbladder stump so metal clip was applied on cystic duct to ensure safety and for that those tow patient were excluded from the study .

\section{Procedures}

Both groups underwent the same procedure with the tow different technique. 
Patients were placed in the supine position on operation table. After giving general anesthesia, pneumo-peritoneum was created using a verses needle inserted through a small skin incision in infraumblical region.

In (Group-B), 4 ports were placed then the fold of peritoneum covering the cystic artery, cystic duct and lymph node were dissected and the junction between the gallbladder and the cystic duct was established and the cystic duct was dissected to the common bile duct.

Gall bladder was separated from its bed using spatula or electro-hooks. In study group (Group-A), 3 ports only were placed the fold of peritoneum covering the cystic artery, cystic duct and lymph node were dissected using a harmonic scalpel as an energy sealing devices.

Gallbladder extraction was similar in both groups. Postoperative pain was assessed at 12, 24 , and $48 \mathrm{~h}$ and 1 week after visual analog scale (VAS) surgery; postoperative analgesia (NSAID) was administered intramuscularly, if necessary. When patients were already affected by pain, a potent analgesic $(1 \mathrm{mg} / \mathrm{kg}$ of intramuscular pethidine) was prescribed and cumulative doses of this medicine were given.

All intraoperative variants as operative time, type of anaethesia learning curve and intraoperative variants as analgesics requirement, hospital stay, postoperative complications (as hemorrhage, biliary fistula, infection) postoperative complication i.e.-cystic duct leak, cystic artery bleed or any other collection subsequent surgery and average hospital stay.

Regular follow-up was performed for all patients at the outpatient clinic every week up to 6 month for follow up to assess the postoperative complications.

\section{Ethical consideration}

All patients had informed consent that they were involved in the study. An approval was obtained from the Committee on Research Ethics at the Faculty of Medicine in Benha.

\subsection{Statistical analysis}

Table (1) Operative time and Intraoperative blood loss in both group.

\begin{tabular}{lcccc}
\hline Operative time & Group A (N=20) & $\begin{array}{c}\text { Group B } \\
(\mathbf{N = 2 0})\end{array}$ & $\begin{array}{c}\text { Total } \\
(\mathbf{N = 4 0})\end{array}$ & P-value \\
\hline Mean duration (min) & 37.28 & 49.5 & 43.28 & $<0.001$ \\
Minimum duration (min) & 32 & 52 & 32 & \\
Maximum Duration (min) & 61 & 72 & 72 & \\
Standard deviation & 7.86 & 8.053 & 10.01 & \\
Intraoperative blood loss (ml) & & & & \\
Mean & 33 & 73 & 43.28 & $<0.02$ \\
Minimum & 20 & 32 & 20 & \\
Maximum & 56 & 70 & 70 & \\
\hline
\end{tabular}

Table (2) Intraoperative pile spillage and Cases converted to open surgery in both group in both group.

\begin{tabular}{lcc}
\hline Groups & Pile spillage & $\%$ \\
\hline Group A $(\mathbf{N}=20)$ & 0 & 0 \\
Group B $(\mathbf{N}=\mathbf{2 0})$ & 1 & 5 \\
\hline
\end{tabular}


Table (2) Continue

\begin{tabular}{lcc}
\hline Groups & Cases converted & $\%$ \\
Group A $(\mathbf{N}=\mathbf{2 0})$ & 1 & 5 \\
Group B $(\mathbf{N}=\mathbf{2 0})$ & 2 & 10 \\
\hline
\end{tabular}

Table (3) Post-operative pain Score in both group (using VAS score).

\begin{tabular}{lccc}
\hline Score & Group A $(\mathbf{N}=\mathbf{2 0})$ & Group B $(\mathbf{N}=\mathbf{2 0})$ & P-Value \\
\hline Mean pain score & 1.772 & 2.18 & 0.09 \\
Minimum pain score & 1 & 2 & \\
Maximum pain score & 3 & 4 & \\
Standard deviation & 0.548 & 0.54 & \\
\hline
\end{tabular}

Table (4) Amount of drainage in both group.

\begin{tabular}{lcccc}
\hline $\begin{array}{l}\text { Amount of } \\
\text { drainage }\end{array}$ & $\begin{array}{c}\text { Group A } \\
(\mathbf{N = 2 0})\end{array}$ & $\begin{array}{c}\text { Group B } \\
(\mathbf{N = 2 0})\end{array}$ & $\begin{array}{c}\text { Total } \\
(\mathbf{N}=\mathbf{4 0})\end{array}$ & P-Value \\
\hline Mean & 31 & 43 & 43.28 & $<0.03$ \\
Min. & 23 & 30 & 23 & \\
Max. & 60 & 73 & 73 & \\
\hline
\end{tabular}

Table (5) Hospital stay (in days) in both group.

\begin{tabular}{lccc}
\hline Hospital stay (in days) & Group A (N=20) & $\begin{array}{c}\text { Group B } \\
(\mathbf{N}=20)\end{array}$ & P-Value \\
\hline Mean (days) & 2.21 & 2.24 & 0 \\
Minimum (days) & 1 & 1 & \\
Maximum (days) & 4 & 7 & \\
Std. deviation & 0.876 & 1.154 & \\
\hline
\end{tabular}

Table (6) Post-operative infection and post-Operative bile leak in both group.

\begin{tabular}{lcc}
\hline Groups & Infection & $\%$ \\
\hline Group A $(\mathbf{N}=\mathbf{2 0})$ & 1 & 5 \\
Group B $(\mathbf{N}=\mathbf{2 0})$ & 2 & 10 \\
Groups & Bile leak & $\%$ \\
Group A $(\mathbf{N}=\mathbf{2 0})$ & 0 & 0 \\
Group B $(\mathbf{N}=\mathbf{2 0})$ & 0 & 0 \\
\hline
\end{tabular}

\section{Discussion}

In our analysis, the mean working time for the harmonic group was significantly shorter than for the regular group (37.28 min vs. $49.5, \mathrm{p}=0.0001)$. Samer et al. [8] concluded that statistically significant shorter average running time in Group A may be due to many factors; ACE is a multi-functional device. Replaces four instruments that are widely used in the LC, In other terms, a dissecting device, a clip package, a scissor and an electrosurgery hook or a spatula. Finally, the activation of the harmonic ACE does not produce smoke, which allows the surgeon to perform in a direct field of action during surgery.

Tebala et al [9] have shown that, due to the various functions of energy sealing devices, 4 instruments can be replaced by energy sealing devices. It reduces the need for instrument adaptation, shortening the time of operation, whereas in conventional electrocautery techniques repeated adjustments (extraction and reinsertion) of instruments may increase the risk of tissue injury, such as the intestine or the liver.

In our study, intraoperative blood loss was significantly higher in the conventional group than in the A group ( $73 \mathrm{ml}$ vs. $33 \mathrm{ml} \mathrm{p}=0.0001)$. Huscher et al. [10] argued that energy sealing systems have been shown to be effective and safe for dissection and haemostasis.

This is consistent with studies performed by Mahabaleshwar et al [11] and Gelmini et al [12] that no major intraoperative or postoperative bleeding (blinding) has occurred in either class.

The main finding of this analysis is the absence of any minor or substantial leakage of bile from the cystic duct stump in Group A, which means that the harmonic shears are as stable and as successful as the simple metal clips to cover the stump in the LC. Samer et al. (8) recorded the same result in the absence of either minor or significant bile leaks from the cystic duct stump.

Huscher et al. [10] found Bile leakage was found in seven of the 331 patients (2.1 per cent) in whom only 
harmonic shears were able to close and isolate the cystic duct. This rate of cystic-duct leakage is similar to the $2 \%$ rate recorded in the literature by the use of other cystic-duct closing techniques [22-24].

Different forms of cystic-duct leakage are caused by an improper closing of the duct due to the dislocation of the clip muscles, the necrosis of the duct at the clip point, or the sliding of the clips from the end of the duct and the migration to the biliary duct [13].

Ultracision was associated with a statistically significant lower incidence of perforation of the gallbladder compared to electrocautery (7.1 percent vs. 18.6 percent, respectively; $\mathrm{p}=0.04$ ) as reported in [14] studies.

Samer et al. [8] stated the use of harmonic ACE was correlated with a statistically marginally lower frequency of perforation of the gallbladder relative to electrocautery (10 percent vs. 30 percent).

In our group A sample, the mean post-operative pain score was $(1,772)$, while the mean post-operative pain score was $[2,18]$ in group B (using VAS score). There is no statically significant difference in Post-Operative Pain Score between two groups.

In a study conducted by Kandil et al. [15] who reported a substantially higher incidence of pain in the average population. This statistical difference may be attributed to many factors, such as shorter time of operation, as we use less gas and less gale bladder perforation in the harmonic group and less bile leakage in the peritoneum.

The mean amount of postoperative drainage in our sample was more in the conventional group than in the group (43 vs. $31 \mathrm{ml}$ ) the hospital stay in group A was shorter (2.21 vs. 2.24 days).

This is consistent with the result of a study conducted by Kandil et al. [15] who reported that the mean volume of postoperative drainage in the conventional cholecystectomy group was significantly higher than in the energy sealing group. In our sample the hospital stay in group B was shorter than group A $(20.15 \pm 5.65$ vs. $24.65 \pm 6.22, P=0.006)$. This is in agreement with the result of a study carried out by Huscher et al. [10] indicated that the hospital stay was shorter in the energy sealing category than in conventional cholecystectomy. It is in line with the findings of the analysis carried out by Kandil et al. [15] who reported that the hospital stay in the Energy sealing devices category was shorter.

\section{Conclusion}

Energy sealing devices can be used safely in laparoscopic cholecystectomy for control of cystic duct and cystic artery with less operative time and less intraoperative bleeding.

\section{References}

[1] V.Gupta. ABCD of Safe Laparoscopic Cholecystectomy: Imbibing Universal Culture of Safety in Cholecystectomy. Indian J Surg,2018.

[2] M. Barrett, H.J.Asbun, H.L.Chien. Bile duct injury and morbidity following cholecystectomy: a need for improvement. Surg Endosc,2018.

[3] C.C. Yao, H.H. Wong, C.C.Chen. Migration of endoclip into duodenum. Surg Endosc.Vol.15,PP.217. ,2001.

[4] A.Chauhan, A.Gangji, A.Singhal. Control of Cystic Artery Using Monopolar Electrocautery in Laparoscopic Cholecystectomy: Our Experience. Sch. J. APP. Med. Sci.Vol. 2,PP.1381-82.10,2014.

[5] J.F.Amaral. The experimental development of an ultrasonically activated scalpel for laparoscopic use. Surg Laparosc Endosc.Vol. 4,PP.92-99. 11,1994.

[6] J.Westrvelt Clipless. cholecystectomy: broadening the role of the Harmonic scalpel. JSLS.Vol.283-285 ,2004.

[7] D.Gossot, G.Buess, A.Cuschieri. Ultrasonic dissection for endoscopic surgery. Surg Endosc.Vol. 13,PP.412-417,1999.

[8] S.Samer Bessa, H.Alaa. A.Abdel-Razek. Laparoscopic Cholecystectomy in Cirrhotic. J Laparoendosc Adv Surg Tech.Vol. 21(1),PP.15,2011.

[9] G.Tebala. Three-port laparoscopic cholecystectomy by Harmonic dissection without cystic duct and artery clipping. Am J Surg.Vol.191,PP.718-20,2006.

[10] C.G.S.Huscher, M.M.Lirici, M.Di Paola. laparoscopic cholecystectomy by ultrasonic dissection without cystic duct and artery ligature. Surg Endosc.Vol. 17,PP.442-451,2003.

[11] V.Mahabaleshwar, L.Kaman, J.Iqbal. Monopolar electrocautery versus ultrasonic dissection of the gallbladder from the gallbladder bed in laparoscopic cholecystectomy: a randomized controlled trial. Can J Surg.Vol.55,PP.307-11,2012.

[12] R.Gelmini, C.Franzoni, S.Zona. Laparoscopic Cholecystectomy With Harmonic Scalpel. JSLS. Vol.14,PP.14-19,2010.

[13] L.D.Reis. Surgical clips incorporated into a duodenal ulcer: a rare complication after elective laparoscopic cholecystectomy. Endoscopy.Vol. 32:S3,2000.

[14] I.M.C.Janssen, D.J.Swank, O.Boonstra. Randomized, clinical trial of ultrasonic versus electrocautery dissection of the gallbladder in laparoscopic cholecystectomy. $\mathrm{Br} \mathrm{J}$ Surg.Vol. 90,PP.799-803. ,2003.

[15] T.Kandil, A.M.El Nakeeb, E.El Hefhawy. Comparative study between laparoscopic conventional cholecystectomy and clipless cholecystectomy using harmonic scalpel. J Gastrointest Surg.Vol. 14,PP.323-328. 19.,2010. 